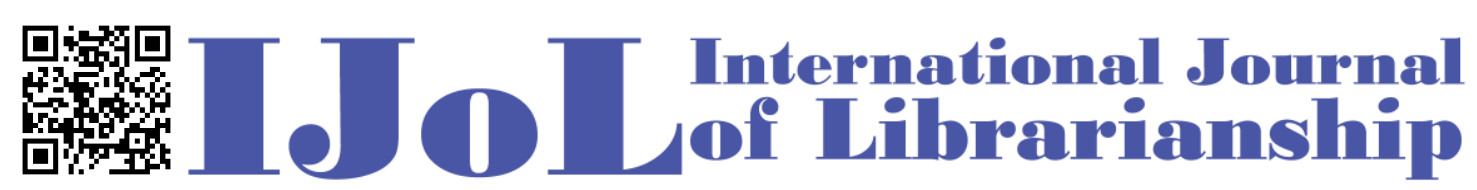

ISSN: 2474-3542 Journal homepage: http://journal.calaijol.org

\title{
The Concept, Design, Implementation, and Assessment of Case-Based Learning in an Information Literacy Classroom
}

Junli Diao

\begin{abstract}
:
Case-Based Learning (CBL) is a popular and successful teaching method used for a long time in disciplines such as medicine, business, law, and computer science. In the past decade, there has been a trend to introduce CBL into library instructions as an active teaching approach in the field of library and information science. Although a few studies have been conducted to investigate the advantages of this teaching technique in the library and information science literature, there remains a substantial absence of first-hand instructional experiences and observations from academic librarians who are actively teaching information literacy. This article presents a personal account of the concept, design, implementation, and assessment of CBL in an information literacy classroom. It discusses the advantages and limitations of CBL, offers suggestions for the future, and points out potential concerns related to the evaluation of workload, librarians' responsibilities, and the workplace culture. Based on experiences and assessments of CBL classes, the article outlines foreseeable challenges for teaching librarians planning to implement CBL program in information literacy education.
\end{abstract}

To cite this article:

Diao, J. (2020). The Concept, Design, Implementation, and Assessment of Case-Based Learning in an Information Literacy Classroom. International Journal of Librarianship, 5(1), 108-127. https://doi.org/10.23974/ijol.2020.vol5.1.156

To submit your article to this journal:

Go to https://ojs.calaijol.org/index.php/ijol/about/submissions 


\title{
The Concept, Design, Implementation, and Assessment of Case- Based Learning in an Information Literacy Classroom
}

\author{
Junli Diao \\ The City University of New York, NY, USA
}

\begin{abstract}
Case-Based Learning (CBL) is a popular and successful teaching method used for a long time in disciplines such as medicine, business, law, and computer science. In the past decade, there has been a trend to introduce CBL into library instructions as an active teaching approach in the field of library and information science. Although a few studies have been conducted to investigate the advantages of this teaching technique in the library and information science literature, there remains a substantial absence of first-hand instructional experiences and observations from academic librarians who are actively teaching information literacy. This article presents a personal account of the concept, design, implementation, and assessment of CBL in an information literacy classroom. It discusses the advantages and limitations of CBL, offers suggestions for the future, and points out potential concerns related to the evaluation of workload, librarians' responsibilities, and the workplace culture. Based on experiences and assessments of CBL classes, the article outlines foreseeable challenges for teaching librarians planning to implement CBL program in information literacy education.
\end{abstract}

Keywords: CBL, case-based learning, PBL, problem-based learning, active learning, IL, information literacy, case teaching

\section{INTRODUCTION}

The Biology Department at York College of the City University of New York (CUNY) offers students courses in life sciences to advance their studies. These courses provide non-science majors with basic education in biological concepts and biological discoveries that solve social and environmental problems (The Biology Department of York College, 2019). Nine years ago, the York College Library began collaborating with the Biology Department to integrate one-shot information literacy instructions into the Biological Principles I, Bio 201 in abbreviation, (Liberal Arts). All the librarians at York College Library have been equally participating in teaching information literacy sessions. The library not only gives value to the traditional lecturebased teaching to ensure successful delivery of information literacy instruction, but also leaves freedom to individual librarians who favor intentional, innovative, and learner-centered pedagogical approaches to cater to the growing needs of students. This article records one librarian's teaching experience in this aspect, which documents the utilization of the Case-Based Learning (CBL) in the one-shot information literacy classes. The goal of these classes is to help 
students become more competent, confident, and critical information seekers. Furthermore, these classes aim to assist students in achieving deeper learning both in their current academic lives and future professional lives.

\section{LITERATURE REVIEW}

CBL is considered as a variation or a subset of Problem-Based Learning (PBL) (Carder, Willingham, \& Bibb, 2001; Snavely, 2004). It is not possible to discuss CBL without giving credit to PBL, which is an open, curriculum-driven, educational philosophy that emphasizes the journey of the learner and the process followed to solve a problem. PBL was first developed by the Medical School of McMaster University in Ontario, Canada, in the 1960s. During the mid1980s, some librarians ventured out of the libraries and gradually became involved with PBL (Koufogiannakis, Buckingham, Alibhai, \& Rayner, 2005). In recent decades, librarians increasingly stepped into PBL curricula and played an indispensable role by integrating library instructions, resources, and facilities into this educational innovation (Chen, Lin, \& Chang, 2011; Cook \& Walsh, 2012; Fallon \& Breen, 2005; Fridén, 1996; Hines \& Hines, 2012; Satterthwaite, Helms, Nouravarsani, Van Antwerp, \&Woelfl, 1995; Wenger, 2014). At the same time, librarians were tempted by the nature of PBL as an engaging, collaborative, constructive, exploratory, and active learning method. They introduced PBL into library orientations to offer students a relaxing and entertaining environment to reduce library anxiety (Angell \& Boss, 2016), or modified PBL into one-shot information literacy instructions with the understanding of its complexity and limitations (Kenney, 2008; Munro, 2006; Stevens \& Teiman, 2017).

As emerging, recognizable teaching pedagogies, PBL and CBL both feature storytelling. However, the stories involved are different in nature and serve different purposes. Stories in PBL provide guidance to curricula and tend to be vague, complex, or ill-defined for good purpose. Students are left responsible for their own learning while instructors step aside and act as facilitators. Stories in CBL tend to be short, controversial, contemporary, and engage interesting characters; they are planned to stimulate dialogues and force decisions (Herreid, 1998). More importantly, CBL demonstrates more flexibility which can be either vertically integrated into the curriculum to emphasize the continuity of knowledge from one lesson to next, or horizontally, to highlight the linkage of knowledge across different disciplines (Williams, 2005). CBL can be applied as a series during a semester and distributed to small groups to analyze, discuss, and present their observations and conclusions; or it can be simply used in a lecture-based class to engage students in discussions in order to make the lesson more interactive, refreshing, and interesting. Recent cognitive research challenged PBL and found that simple, discrete items generated longer and better information recall than a mass of complex, distracting information (Van Merrienboer \& Sweller, 2005, cited in Hays 2008, p. 74). Therefore, the one-shot, onehour-based information literacy sessions that have a content specificity and advocate the mastery of information retrieval skills may limit the effective use of PBL. The straightforward, flexible CBL approach is a more plausible solution to overcome the time restriction and help both librarians and students gain the most from information literacy education.

The considerable benefits of CBL have been acknowledged by some library school professors and librarians. Dow et al. (2015) used cased-based instruction in their graduate courses on library and information science and stated "there is evidence that case-based 
instruction increased students' knowledge of basic principles of information ethics and enhanced the learning process" (p. 156). Foster (2017) integrated a wine business case study in library instruction to prepare students for their careers. The results demonstrated that in a CBL situation, students effectively developed the ability to use existing information to create new information in their business plans. It also showed that CBL had potential value in teaching students complex information literacy skills to support their career preparation. Spackman and Camacho (2009) articulated that "this storytelling element captures student interest and accentuates the inductive and constructivist nature of learning through cases" (p. 549). Students' narrative responses in their study strengthened researchers' argument that further research should be conducted in the field to generate improved performance on students' learning and class assignments. The literature demonstrates CBL's significant benefits to students and librarians. However, a substantial amount of work is still left for academic librarians to explore the potential use of CBL as a worthwhile instructional technique to create a dynamic, interactive learning environment. Particularly, the literature has an absence of the first-hand instructional experience from academic librarians on the frontline. This article seeks to fill in the gap through sharing personal instructional experience that covers the full cycle of CBL from concept, design, implementation, and assessment.

\section{CASE CONCEPT}

Integrating information literacy instruction into Bio 201 at York College, the City University of New York, was the outcome of joint efforts by the biology faculty and librarians' team in 2010 (Drobnicki, personal communication, October 30, 2019; Su, personal communication, October 31, 2019). Since then, this instruction has been consistently practiced in the library's information literacy classroom or the labs in the Biology Department in fall and spring semesters. Approximately 500 students benefit from librarians' instruction every year. Initially provided by the biology faculty, the instruction worksheet (see Appendix A) synthesized two models from the South Plains College in Texas and the Loyola Marymount College in California and was last updated in 2016 ( $\mathrm{Su}, 2019)$. It is a librarian's responsibility to help students learn to access and choose appropriate databases, use keywords with Boolean Operators, cite resources, and other things that librarians believe helpful to the class ( $\mathrm{Su}, 2019)$. After the librarian's instruction, the classroom faculty takes over the class and guide students to read, analyze, and evaluate articles retrieved by students and complete their assignments.

The instructing librarian and author of this article (hereafter referred to as the librarian) joined the library in 2015 and started teaching information literacy in 2016. After a careful study of the worksheet and a couple of classroom observations, the librarian believed that students had some difficulty in understanding how to "devise three search terms related to your independent study project." While instructions were over, students might still have had lingering questions from the worksheet, such as:

1. Why do the search terms have to be three?

2. What if I have two search terms and where and how can I find the third one?

3. Where do the search terms come from and how do they relate to my independent study project?

4. How do I "devise" search terms from my independent study project? 
5. What if I don't have a clear idea what my independent study project could be? Where could I find things that will offer me some inspiration?

This worksheet requires librarians to teach students:

1. How to access the library's databases, both on campus and off campus;

2. How to choose and search databases;

3. What are the differences between popular resources and scholarly resources;

4. What a peer-reviewed article is;

5. Why a peer-reviewed article is important for college studies.

After analyzing the requirements listed above, the librarian realized that the effective time allocated exclusively for the instruction of database usage should be around 40 minutes within a maximum of 60 minutes. An orthodox approach to teach a class should begin with librarians formulating three search terms and using them as an example to demonstrate how to search various databases with Boolean Operators. Then students would have an opportunity to practice what they have observed, ask librarians relevant questions, and practice again. Librarians should offer some appropriate search terms to students who are hesitant or who do not have any search terms in mind. In this way, they will not fall behind other students and keep up with the rest of the class.

The traditional teaching method is straightforward and well-tested. However, often it does not tell students the inherent linkages between the three important search terms they have selected to retrieve information. Essentially, search terms are abstract descriptions of things, ideas and/or behaviors. The concept might be a single word, like "drug," or multiple words, such as "drug addiction." Search terms, or concepts, do not live in segregated vacuums nor come from nowhere. A combination of them could reveal the semantic context. They could be conceptualized from a story, a narrative, a phenomenon, or an event which students observed in their lives or in their own personal readings for academic or leisure purpose. In other words, search terms inhabit a context or a situation, which can be studied, analyzed and conceptualized. If this were done successfully, students would develop more confidence and competence in "devising" search terms. With the analysis of the worksheet and the recognition of possible questions that linger in students' minds, the librarian believed that students' struggles necessitated an alternative pedagogical approach-Case-Based Learning. This approach will put students in a real-life situation to apply past experience or construct new knowledge through exploration and testing.

\section{CASE DESIGN}

"For instructors, the case study method is particularly useful as a way to begin and sustain class discussions, encourage the application of course concepts, and move students from simple to more complex thinking" (McClam \& Woodside, 2005, p. 36). Therefore, a carefully designed case should fulfill multiple educational purposes from facilitating instructors to achieve effective teaching to engaging students in the granularity of the learning realm. Designing cases can be time consuming and it requires a lot of preparation from librarians. The librarian's case designing experience in this article echoes Kenney (2008)'s suggestion that the sources of inspiration for good cases come from news in newspapers, articles in periodicals, reference tools, discussions in 
social media, listservs and other internet utilities, everyday life experiences, casual conversation with families and friends, and other socializing opportunities.

The prototype case used in the librarian's first instruction in 2016 was derived from Google news. Researchers at Brown University examined a frog's jump at 500 frames per second with X-ray filming technology and revealed the secret why frogs are extraordinary jumpers. The librarian was inspired by this news and decided to turn it into a case study for Bio 201 instruction to demonstrate to students how to extract search terms out of a narrative (see Appendix B). This case contains 127 words, followed by four questions. The librarian was conscientious that college freshmen have urgent needs to learn how to find books through Online Public Access Catalog (OPAC). Hence, this single case was used to guide students to learn how to use OPAC through the first two questions and then how to extract search terms to find articles for question number three and four. In particular, the fourth question was intended to stimulate students' interdisciplinary curiosity and expand their horizon from animal biology to engineering and computer science.

This case was deliberately written with the inclusion of multiple synonyms: jump, bounce, and leap, as well as other distractive terms such as "sling shot," "exceptional jumpers," "unusually longer legs," "Harvard University," and "mechanical systems that imitate the movement of frogs." The inclusion of purposefully designed synonyms and distractive terms was intended to teach students to recognize the value of commonly known terms and identify authorized names of affiliations in databases. The librarian's classes were observed by two senior colleagues in 2017 and 2018. In addition to their positive comments about CBL, critical suggestions included:

1. The case is a little bit too long.

2. OPAC search for books seem to be unnecessary.

3. It is better to design two smaller but different cases to serve different purposes.

The librarian took their suggestions to abridge the existing case, and then designed a second case (see Appendix C), which was derived from a research article published in the New England Journal of Medicine. As a result, two shorter cases were distributed to students in 2019 with two different instructional goals. In the first case, students were required to select key terms from the case. The second case assisted students to formulate plausible research questions, from which three key terms were extracted to locate related articles. A hidden purpose embedded in the second case was that students would be guided to articulate possible synonyms for the "88year-old man" and understand the significance of their search in attempting to retrieve comprehensive results. In designing these two cases, the librarian followed the principle of "from-easy-to-difficult," with gradual improvement in students' learning.

\section{CASE DELIVERY}

Designing good cases are always time-consuming and effort-demanding, but it is just the first step of CBL. Good cases will not guarantee a successful instruction in a time-controlled information literacy class. Continued and revised planning is necessary in a well-structured classroom for successful classroom management. Plus, the librarian's personalized teaching style will help to achieve all pedagogical goals. 


\section{Creating a Lesson Plan}

A lesson plan is a linear, procedural, detailed description of the proposed teaching steps, learning activities, and support materials involved in a lesson or series of lessons. It defines goals and objectives to be achieved, as well as the method and activities to be used to achieve these goals. In addition, a well-designed lesson plan leaves room to keep anecdotes and personal reflection for adjustment for future lessons. The librarian's classes evidenced that in a case-based information literacy instruction, keeping activities and sessions adherent to a timeline developed beforehand can be challenging. However, experience also showed that a well-written lesson plan will help reduce the feeling of being overwhelmed or unprepared. Otherwise, absence of a lesson plan could result in a lack of confidence or lead to spending extra effort in managing behavior problems in the classroom with unnecessary confusion or struggle.

\section{Lead-In Activity}

The librarian's experience suggested that opening the case instruction with a brief lead-in activity will help guide students into the scene and facilitate their understanding of the intention of the case. A typical introductory example in the librarian's class went like this. Students were asked to raise their hands if they liked gardening. If no one answered, the librarian could ask whether anyone in the class lived in a community that had a park or liked walking in the park. Then the librarian asked whether they like planting or watching flowers which attracts butterflies and why. The librarian continued that "butterfly" would become a searching term if they wanted to do a study on butterflies. Then the librarian suggested a scenario that no butterflies came to visit flowers this year and heavy smoke kept coming from the chimney of a local factory. This introduced the second term "air pollution" or "global warming" to those who were drawn to this topic. A lead-in activity could take various forms, but it should be simple and interactive in order to stimulate the minds of students and help the instructor build rapport with them instantly. Otherwise, immediate exposure to the case will put them in a swim-or-sink situation.

\section{Flexibility of Instruction}

CBL should be flexible in information literacy instruction. It can be included in lecture-based classes where librarians function as the experts and guide students to discuss the cases together. The more popular method is to put students in pairs or small groups, which gives autonomy and freedom to students and promotes active, collaborative learning. The librarian experimented with both approaches. The first case is presented in a straightforward, clear manner where it was an open discussion. The second case is more complicated as it requires students to generate all the possible labeling terms to describe an "88-year-old man." Therefore, this case was tried out as pair discussion in the library's classroom where students sat in a row and each of them had a computer, and then as a small group discussion in biology lab where sometimes three or four students had to share one computer. The exampled research questions generated by students from the second case include, but not limited to, "Are eggs bad food for senior citizens who are having diabetes?" The possible searching term formula demonstrated to students could be "egg AND ("senior citizen" OR "older man" OR "elderly man") AND diabetics" or "egg AND ("senior citizen" OR "older man" OR "elderly man") AND diabetics AND "bad OR unhealthy OR risky." The librarian also reminded students not to limit their research questions to only a specific case but to find their own research questions in the narratives or stories associated with their lives. For 
instance, one immigrant student wrote, "Why do some Haitian women suffer death rate while giving birth to a baby?" This turned out to be a good example to show students the advantage of using the terms, "maternal death" or "maternal mortality" supplied by experts who wrote the articles.

With the librarian's guidance, students took the search terms into a recommended database to explore how it functioned. As this happened, the librarian walked around to observe their activities and answered questions. At the end, the librarian picked some search terms developed by students on the spot and did a demonstration of information retrieval techniques, such as Boolean Operators, usage of quotation marks and database features that filter retrieved results by time, subject, language, and affiliation. The librarian observed that the classroom atmosphere was more stimulating when case studies were used with the personalized teaching approach. In a relaxed learning environment, students were more comfortable and willing to respond to and ask the librarian's questions. They tended to frequently interact with neighboring peers in applying concepts and practicing techniques. Also, they were more willing to share both their problems and interesting ideas with the librarian. During this process, the librarians' role shifted from a lecturer to a facilitator. The librarian felt that CBL was a practical, effective, helpful instructional strategy that helped to increase students' engagement and reduce their learning boredom and fatigue.

\section{CASE ASSESSMENT}

In October 2019, the Biology Department at York College sent out to the library a request for 13 sessions of Bio 201 information literacy classes. The librarian signed out four sessions scheduled on November 1, 7, 11, and 12. Considering the time constraint, the librarian designed a brief survey with four short questions only to assess the effectiveness of these two cases. Open space was left at the end for students to make comments that they believed necessary. The survey was given to students soon after each library instruction was finished. A total of 63 undergraduate students attended four sessions of information literacy classes and 63 responded the survey.

The survey focused on whether students understood the cases and whether the skills taught were helpful for them to select keywords, learn Boolean Operators, and complete their assignments successfully. The result showed that $41.27 \%$ strongly agreed and $55.56 \%$ agreed that the two cases are easy to understand. $3.17 \%$ responded neutral and none disagreed or strongly disagreed (see Chart 1). 


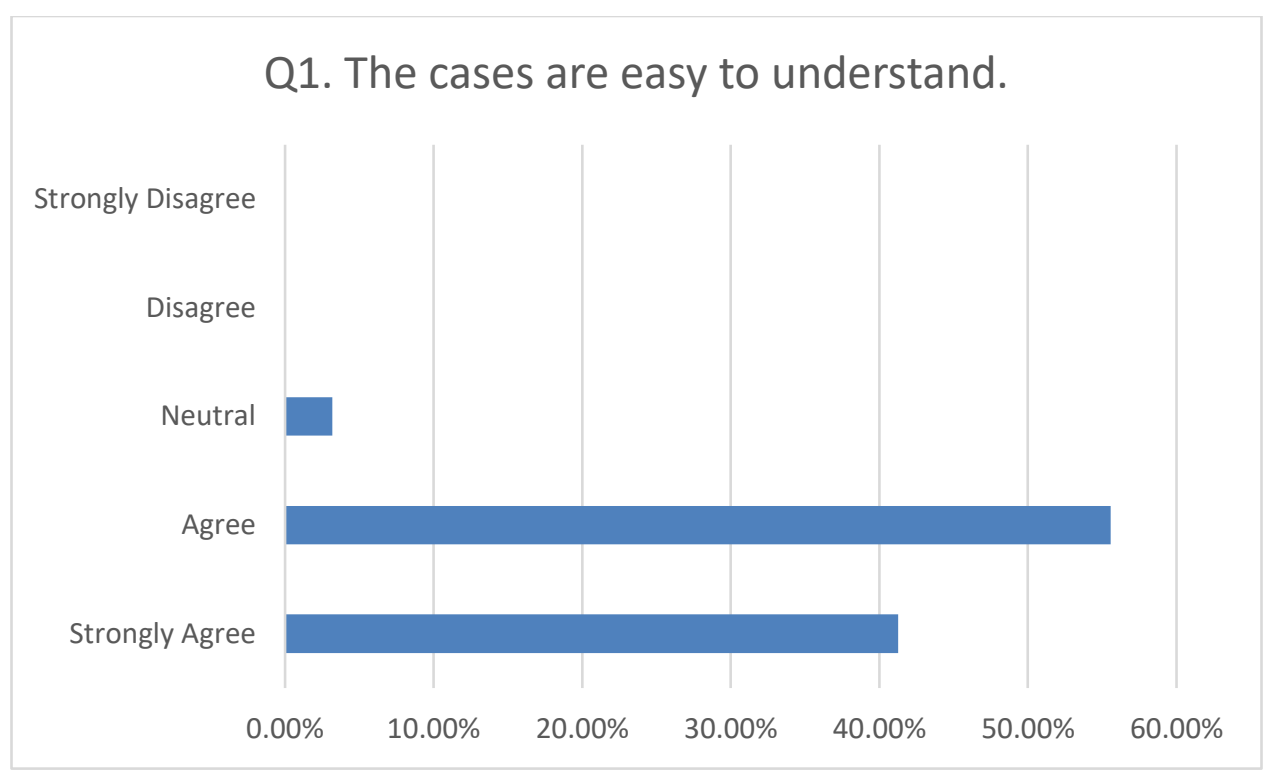

Chart 1. Understanding the cases

$55.56 \%$ strongly agreed and $39.68 \%$ agreed that the cases helped them identify keywords in their own assignment. Meanwhile, $4.76 \%$ were neutral; no one disagreed or strongly disagreed (see Chart 2).

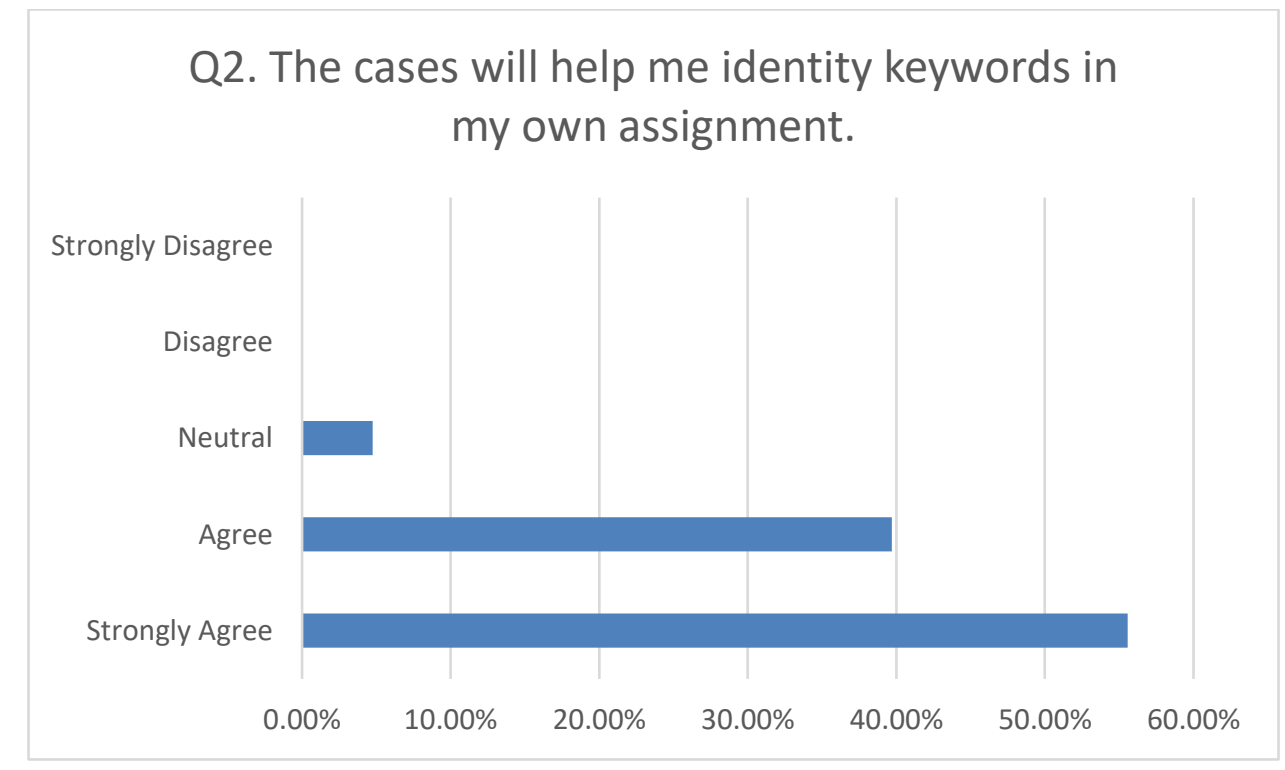

Chart 2. Identifying keywords

To answer the question whether the cases helped them understand the function of Boolean Operators, $53.97 \%$ strongly agreed, 38.09\% agreed, $7.94 \%$ responded neutral, and none of them disagreed or strongly disagreed (see Chart 3 ). 


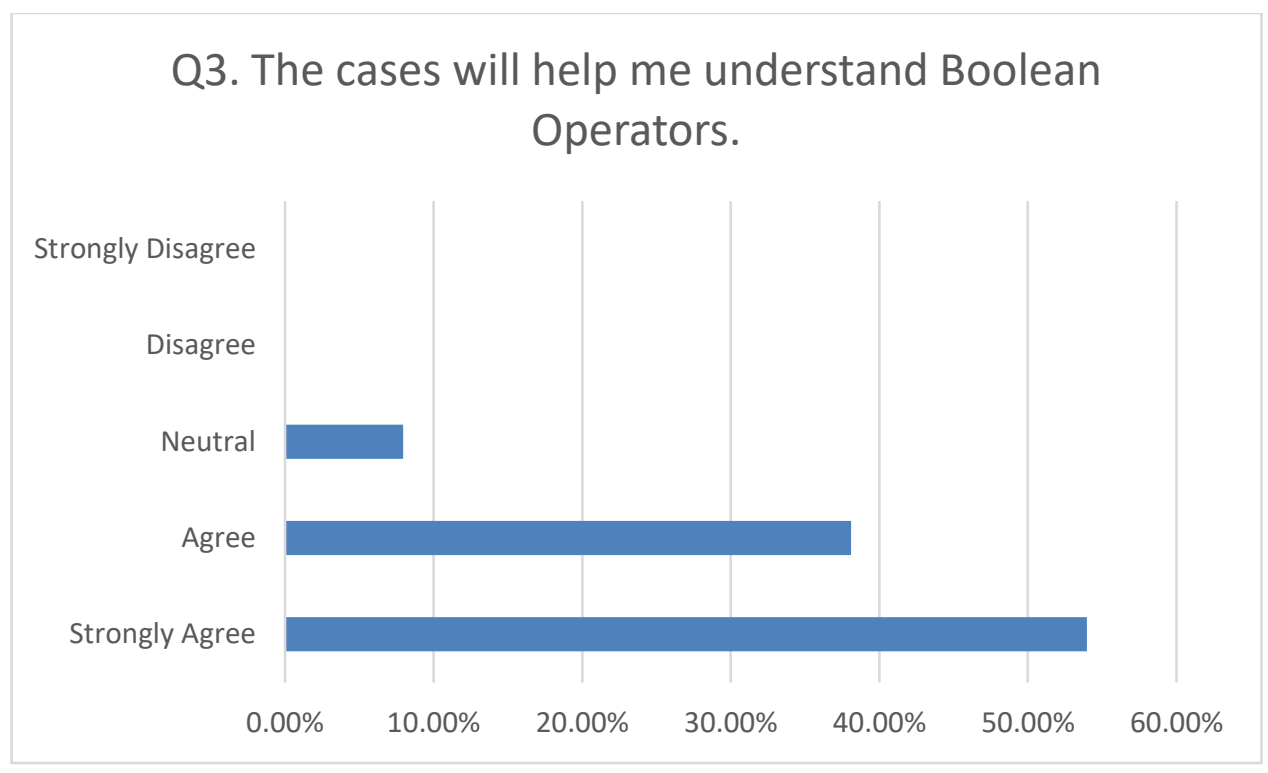

Chart 3. Understanding Boolean Operators

When students were asked whether the cases would help them complete their assignments in the future, $42.86 \%$ strongly agreed, $46.03 \%$ agreed, and $9.52 \%$ were neutral. $1.59 \%$ (one student) disagreed but no one strongly disagreed (see Chart 4).

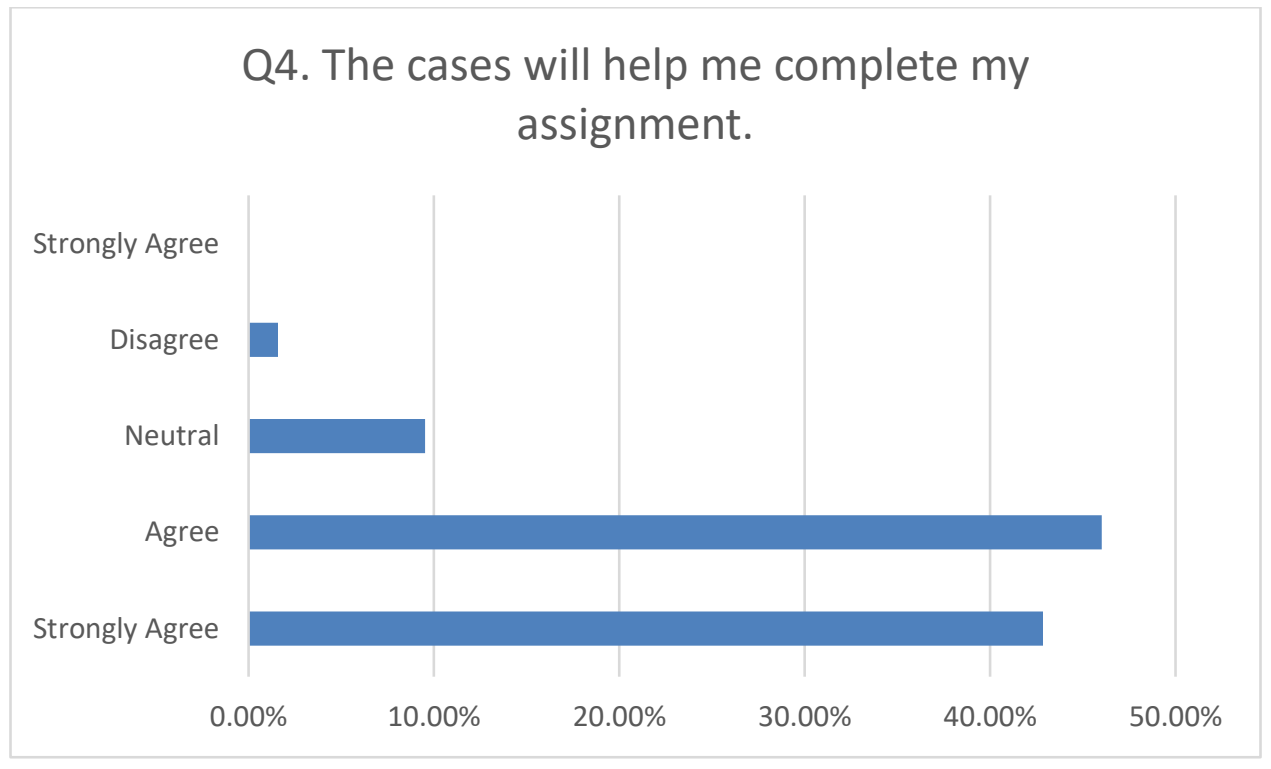

Chart 4. Helping complete assignment

At the end of the survey, an open-ended question gave students the opportunity to write about their comments regarding any aspect of this class. Here is a list of sample comments:

1. The case and the material were really effective and helped bring an easier way to complete the research assignment.

2. It was very easy to understand how to navigate the online library for my research. 
3. He is [a] very good professor.

4. Clear instructions on what to do and how to use search engine.

5. Very good presentation. Very clear.

6. This workshop was really helpful and the instructor was really good.

7. When clicking links and changing websites you went to [too] fast.

8. Thank you. Haven't completed the assignment yet.

Students indeed provided the librarian with a variety of thoughtful comments. They confirmed the effectiveness of instruction, the quality of the instructor, and the quality of the presentation. They also pointed out areas calling for improvement. The richness of students' anecdotal responses demonstrated both their positive and critical attitudes toward case learning and case teaching. The librarian gained a relevant basis upon which this class could be revised and improved for future instruction.

\section{DISCUSSION}

\section{Understanding the Workload}

A good CBL is a systematic project that calls for intensive and ongoing investment of time and effort from the instructor. In a traditional information literacy class, librarians request the course syllabus from the classroom faculty, which probably includes assignments for students. Librarians should spend some time on understand students' needs and informational challenges that students might encounter in the process of completing their assignments. If they consider transforming regular information literacy classrooms into CBL-oriented ones, librarians should be aware that a CBL approach requires extra workload beyond just getting acquainted with students' assignments. The author's personal teaching experience attested that preparing cases that relate to students' assignments and fit in pedagogical objectives can be a daunting task. In addition, librarians must prepare an appropriate teaching plan, decide the best way to introduce and deliver cases, and assess students' learning outcomes. However, once cases are developed, modified, tested, and reach maturity, they can be reused in a similar situation in the future. When that happens, the time and effort that librarians initially invested during the first instructional cycle will make the workload significantly less arduous with only modifications and adjustments to consider. In addition to the eventually reduced workload, the actual instruction should be more relaxing and enjoyable for both instructors and students. Since librarians will have become more familiar with this approach through past experiences, there should also be more improvement in classroom management skills. Librarians should feel more confident to guide discussions and ask open-ended, thought-provoking questions. Both instructional effectiveness and efficiency will be increased.

\section{Understanding One's Own Style and Mind}

CBL, which advocates a learner-centered, active, instructional approach, is not a method suitable for everyone. However, it should be tried by librarians who have curious and innovative minds. Both lecture-based teaching and active learning are good vehicles for information literacy classes, but promote learning with different goals (McDevitt, 2013). It is a tradition that lecture-style instructional approach has long been favored by librarians for various reasons (Munro, 2006). 
Munro also pointed out that librarians must be adaptive to active, flexible instructional methods that consider the immediate research needs of students to facilitate their growing roles as active learners in the real work of research.

Adopting the CBL approach means that the traditional information literacy pedagogy has to be transformed. For this to happen, librarians must be prepared to transform their minds first. Metaphorically speaking, a transformed mind (librarian) serves as the engine that accelerates the vehicle (student). It is most likely that an effective instructional approach can be captured better with suitable and compatible styles and minds. Therefore, before considering to use CBL, librarians have to ask questions like, "Is this teaching approach for me?"; "Am I willing to take this laborious and interactive approach?"; "Am I comfortable with silence when students give no responses to questions asked?; and "am I good at redirecting or elaborating questions to enrich and intensify any discussion?" Perhaps, the most important question is whether one is adventurous and curious enough to try this student inquiry-based approach which sharply contrasts to the traditional instructor-centered approach. A possible risk is that CBL might not be strongly supported by administrators, colleagues, and others in a conservative working culture.

\section{Understanding Workplace Barriers}

The implementation of CBL in information literacy classes not only requires librarians to assess their own traits, but also evaluate what is principally promoted in the working culture of a particular library. Therefore, librarians should be aware of potential challenges and consequences. Barriers from students, colleagues and administrators could possibly hinder educators in their shift from teacher-based instruction to learner-based active instruction. These possible barriers in K-12 environment have been researched and discussed substantially (Herreid, 1997, 2005). Carder, Willingham, and Bibb (2001) in their study concluded that that K-12 students require more structure and shepherding in the classroom, while in comparison, college students tend to be more receptive to a classroom environment that involves problem-solving and lifelong learning. Naturally, this calls for different learning strategies from those used in elementary and high schools. For that reason, the librarian would rather say that college students' needs function as accelerators that drive the implementation of CBL. More importantly, an open-minded, understanding, and supportive library environment helps to nurture different practices and plays a substantial role in the successful implementation of CBL. This was witnessed in the design cases as the librarian in this article received substantial academic freedom from the library department and constructive feedback from senior colleagues. Otherwise, such classroom teaching techniques might be simply considered as offbeat activities. If that happens, it would be important to promote continued education and communication about the advantages and benefits of using the CBL method in college classrooms to demystify this concern.

\section{LIMITATIONS}

Although adopting CBL in the information literacy classroom was refreshing and innovative, it has its limitations in this particular trial. First and foremost, this teaching approach involved statistical analysis of assessment data. However, it cannot be treated with the equal status to empirical research due to its nature as an attempt to share exploratory, personal experience. Another limitation was that the student population involved in the experiment was relatively 
small. Thus, the entire picture about CBL from the student population enrolled in Bio 201 was not fully captured, which leaves much room for improvement in future work.

Last but not least, the data from students, which offered high ratings of their learning outcomes, should be read with caution. Collecting students' self-assessment data in this experimental teaching project was the result of the librarian's impulse of seeking a selfdiagnostic tool to improve teaching. If questions were carefully designed, students' selfassessment data can be treated as an indicator to read their motivation and evaluate learning outcomes (McMillan \& Hearn, 2008). Meta-analysis of past studies demonstrated that the teacher-student relationship and the personalities of teachers both made an impact on students' assessment of learning outcomes and teaching performance (Klassen \& Tze, 2006; Tomcho \& Foels, 2008). In other words, there is a possibility that student's self-reported learning in this experiment could have been the result of a positive rapport the librarian established with students. Therefore, they may have provided a high rating to either encourage the instructor or cover their learning difficulties, or, maybe both. Another factor to consider is the Dunning-Kruger Effect in information literacy classroom setting. Low performers tended to overestimate their achievement in self-reported learning of library skills, and undergraduates inclined to inflate their perceived learning which was often recorded as much higher than graduate students (Mahmood, 2016). Consequently, high-rating assessment data generated from this teaching experiment could include the possibility that some students overrated their learning achievement in this class.

\section{FUTURE WORK}

The initial goal of this teaching experiment was for the librarian to explore the possibility of establishing his own teaching philosophy and to build a personalized classroom instructional style. The librarian may have also hoped that this teaching experiment would raise the awareness of other academic librarians and encourage them to use or try an alternative pedagogical approach. Hopefully, as a result, dialogue between academic librarians who were engaged in CBL teaching and librarians in other colleges or local libraries would be initiated. They could exchange their ideas, reflect on teaching experiences, and offer suggestions and criticisms as professional, critical thinkers.

This concept, design, implementation, and assessment of CBL offers a basic roadmap about how it could work in a library's information literacy classroom. If an informal, individual experiment needs to be upgraded as a collaborative project and tested by a scientific research approach with an attempt to generalize the results, then the whole process should be redesigned. The goals of students' learning should be articulated with pedagogical vision. Information literacy skills that students are expected to acquire should be clearly specified in the instructional plan. The cases should be developed with the involvement of classroom faculty from the Biology Department. By so doing, the cases used in classes should align with curriculum needs, activate students' prior knowledge, and stimulate the generation of new knowledge and skills.

The potential benefits of CBL in this teaching experiment were proven to be many. However, its impact on student learning remains to be further quantified through carefully designed evaluation methods, such as pre and post instruction assessments. These would offer benchmarks to determine how significant differences can be in terms of learning outcomes and teaching effectiveness. When the effectiveness of $\mathrm{CBL}$ is quantitatively and qualitatively 
measured through rigorous research, it will not just be one librarian's undertaking any more. The design, implementation, and assessment would require the participation of motivated librarians and the cross-departmental collaboration with other classroom faculties.

\section{CONCLUSION}

This article presents a basic but complete life cycle of CBL used in an information literacy classroom and covers how cases were developed, delivered, and assessed. Both the librarian's observation and the classroom assessment support the argument that CBL helped to improve students' interaction in classroom as it increased their confidence to learn how to apply library skills and to solve information retrieval problems. At the same time, it must be kept in mind that no instructional method in the information literacy classroom will serve as a one-size-fits-all panacea and the implementation of CBL has its foreseeable challenges.

In past decades, academic librarians have been designing innovative programs and have stepped into emerging instructional roles to assist students to achieve the best learning outcomes. Preparing students to become efficient lifelong learners both in their academic lives and future professional lives requires from librarians the successful delivery of information literacy education on campus and such success should be supported by intentional, reflective, and strategic pedagogical approaches (O'Clair, 2017). Kimberley M. Donnelly, Assistant Professor and Reference Librarian at York College of Pennsylvania, articulated that educational change and reform called for a consideration of well-structured and concrete programs that encouraged librarians to shift their roles from passive teachers to interactive, collaborative, learner-centered educators (2000, p. 59-60). The learning-based program is built on agreeable co-habitation of classroom space shared by both librarians and classroom faculty. Together, they mutually anticipate students' need for information in advance and proactively associate such needs with their levels of learning under a comprehensive instructional paradigm. Donnelly (2000) acknowledged that the success of a learning-based program largely depended on the full support from campus administrations and a positive political climate to encourage both library and classroom faculty to venture into new roles. Otherwise, the confinement from personal nostalgia and political bureaucracy would prevent the library from shifting to a learning-centered institution for both librarians and students.

The concept, design, implementation, and assessment of CBL in this teaching experiment reinforced Donnelly's (2000) argument that the current situation in the library community calls for a learner-centered approach in response to changes happening in technology, student cohorts, and models of pedagogy. The nature of one-shot library instructions means that there is a large possibility that this may be the only chance that librarians and students work together in the same classroom to explore the wonders of the information realm. Therefore, it is totally understandable that librarians put a wholehearted effort into the full and comprehensive coverage of library resources and services through instructor-centered lecturing and demonstrations. Traditional lecturing will continue because the library is by nature a service which necessitates instant application of surface learning. At the same time, it is important for librarians to understand that learning for students is a process that continues beyond the library's walls. Changes in technology, student cohorts, and pedagogical models demand that librarians with innovative

minds take the lead to transform their roles from passive lecturers to active facilitators and 
redefine the landscape of information literacy classroom through implementing active learning. "Give a man a fish and you feed him for a day; teach a man to fish and you feed him for a lifetime."

\section{ACKNOWLEDGMENT}

The author wants to give special gratitude of thanks to Chief Librarian, Professor Njoki Kinyatti, for her freedom and support given to implement this teaching approach. The author wants to offer his sincere appreciation to Professor John Drobnicki and Professor Scott Sheidlower for their valuable observations. The author would also like thank the two anonymous reviewers for critically reading the manuscript and suggesting substantial improvements.

\section{References}

Angell, K., \& Boss, K. (2016). Adapting the Amazing Library Race: Using problem-based learning in library orientations. College \& Undergraduate Libraries, 23(1), 44-55. https://doi.org/10.1080/10691316.2014.935547

Biology Department of York College. (2019). Welcome to the Department of Biology.

Retrieved November 16, 2019 from https://www.york.cuny.edu/academics/departments/biology

Carder, L., Willingham, P., \& Bibb, D. (2001). Case-based, problem-based learning: Information literacy for the real world. Research Strategies, 18(3), 181-190. https://doi.org/10.1016/S0734-3310(02)00087-3

Chen, K. N., Lin, P. C., \& Chang, S. S. (2011, September). Integrating library instruction into a problem-based learning curriculum. In Aslib Proceedings, 63(5). Emerald Group Publishing Limited. https://doi.org/10.1108/00012531111164996

Cook, P., \& Walsh, M. B. (2012). Collaboration and problem-based learning: Integrating information literacy into a political science course. Communications in Information Literacy, 6(1), 59-72. https://doi.org/10.15760/comminfolit.2012.6.1.118

Donnelly, K. M. (2000). Building the learning library: Where do we start? In A. H. Bahr (Ed.) Future Teaching Roles for Academics Librarians (pp. 59-75). New York, NY: Haworth Press.

Dow, M. J., Boettcher, C. A., Diego, J. F., Karch, M. E., Todd-Diaz, A., \& Woods, K. M. (2015). Case-based learning as pedagogy for teaching information ethics based on the Dervin sense-making methodology. Journal of Education for Library and Information Science, 56(2), 141-157. https://doi.org/10.3138/jelis.56.2.141

Fallon, H., \& Breen, E. (2005). Developing student information literacy skills to support project and problem-based learning. Retrieved from http://eprints.teachingandlearning.ie/2208/1/Fallon\%20and\%20Breen\%202005.pdf.

Foster, B. (2017, September). Professional practice: Using case studies in information literacy instruction towards career readiness. In European Conference on Information Literacy (pp. 119-127). Springer: Cham.

Fridén, K. (1996). The librarian as a teacher: Experiences from a problem-based setting. Health Libraries Review, 13(1), 3-7. https://doi.org/10.1046/j.13652532.1996.1310003.x.

Herreid, C. F. (1997). What makes a good case? Some basic rules of good storytelling help teachers generate student excitement in the classroom. Journal of College Science Teaching, 27, 163-165. 
Herreid, C. F. (1998). Why isn't cooperative learning used to teach science? BioScience, 48, 553-559.

Herreid, C. F. (2005). Using case studies to teach science. Education: classroom methodology. American Institute of Biological Sciences. Retrieved October 10, 2019 from https://files.eric.ed.gov/fulltext/ED485982.pdf.

Hines, S., \& Hines, E. H. (2012). Faculty and librarian collaboration on problem-based learning. Journal of Library Innovation, 3(2), 18-32.

Hays, R. (2008). A practical guide to curriculum design: Problem-based, case-based or traditional? The Clinical Teacher, 5(2), 73-77. https://doi.org/10.1111/j.1743-498X.2007.00191.x

Kenney, B. F. (2008). Revitalizing the one-shot instruction session using problem-based learning. Reference \& User Services Quarterly, 47, 386-391. https://www.jstor.org/stable/20864946.

Klassen, R. M., \& Tze, V. M. C. (2014). Teachers' self-efficacy, personality, and teaching effectiveness: A meta-analysis. Educational Research Review, 12, 59-76. http://dx.doi.org/10.1016/j.edurev.2014.06.001

Koufogiannakis, D., Buckingham, J., Alibhai, A., \& Rayner, D. (2005). Impact of librarians in first-year medical and dental student problem-based learning (PBL) groups: A controlled study. Health Information \& Libraries Journal, 22(3), 189-195. https://doi.org/10.1111/j.1471-1842.2005.00559.x.

McClam, T., \& Woodside, M. (2005). Using case studies: An international approach. International Education, 34(2), 36-45.

McDevitt, T. (2013). Everyone likes a challenge: Getting students' attention with interactive games and authentic assignments. Pennsylvania Libraries: Research \& Practice, 1(2), 149-161. https://doi.org/10.5195/palrap.2013.25

McMillan, J. H., \& Hearn, J. (2008). Student self-assessment: The key to stronger student motivation and higher achievement. Educational Horizon, 87(1), 40-49.

Mahmood, K. (2016). Do people overestimate their information literacy skills? A systematic review of empirical evidence on the Dunning-Kruger Effect. Communication in Information Literacy, 10(2), 199-213. https://doi.org/10.15760

Munro, K. (2006). Modified problem-based library instruction: A simple, reusable instruction design. College \& Undergraduate Libraries, 13(3), 53-61. https://doi.org/10.1300/J106v13n03_04.

O'Clair, K. (2017). Intentionally planning information literacy instruction. In B.West, K. D. Hoffman, \& M. Costello (Eds.), Creative Instructional Design: Practical Applications for Librarians (pp. 11-28). Chicago: Association of College and Research Libraries.

Satterthwaite, R. K., Helms, M. E., Nouravarsani, R., Van Antwerp, M., \& Woelfl, N. N. (1995). Library faculty role in problem-based learning: Facilitating small groups. Bulletin of the Medical Library Association, 83, 465-468.

Snavely, L. (2004). Making problem-based learning work: Institutional changes. portal: Libraries and the Academy, 4, 521-531.

Spackman, A., \& Camacho, L. (2009). Rendering information literacy relevant: A case-based pedagogy. The Journal of Academic Librarianship, 35, 548-554. https://doi.org/10.1016/j.acalib.2009.08.005.

Stevens, E., \& Tieman, A. (2017). We used problem-based learning in library instruction and came to question its treatment of students. The Library with the Lead Pipe. Retrieved October 10, 2019 from http://www.inthelibrarywiththeleadpipe.org/2017/we-usedproblem-based-learning-in-library-instruction-and-came-to-question-its-treatment-ofstudents/

Tomcho, T. J., \& Foels, R. (2008). Assessing effective teaching of psychology: A meta-analytic integration of learning outcomes. Teaching of Psychology 35(4), 286-296. 
Wenger, K. (2014). Problem-based learning and information literacy: A natural partnership. Pennsylvania Libraries: Research \& Practice, 2(2), 142-154. https://doi.org/10.5195/palrap.2014.61.

Williams, B. (2005). Case based learning - a review of the literature: Is there scope for this educational paradigm in prehospital education? Emergency Medicine Journal, 22(8), 577-581. http://dx.doi.org/10.1136/emj.2004.022707

Van Merrienboer, J. J., \& Sweller, J. (2005). Cognitive load theory and complex learning: Recent developments and future directions. Educational Psychology Review, 17(2), 147177.

\section{About the author}

Junli Diao is an Assistant Professor/Head of Cataloging and Serials, York College Library of the City University of New York. His current research includes information literacy pedagogy and innovations, and academic librarians' identity construction. 


\section{Appendix A. Bio 201 Lab Worksheet}

\section{Bio $201 \quad$ Name}

\section{Lab 10: Library Research}

In this week's lab, you will become familiar with the college's online library resources. You will enjoy a lecture from a member of the library faculty about finding journal articles from the peer reviewed literature. The following assignment, adapted from assignments given in Biology 1406 at South Plains College in Texas and in Biology 112 at Loyola Marymount College in California, must be completed by each student individually. Please attach a copy of your article to the assignment.

1. Devise three search terms related to your independent study project. (i.e. reaction timefear - heart rate)

2. Conduct your search using one of the databases described by the librarian. Reminder: you are looking for peer reviewed journal articles, not web pages. Google is not a suitable search engine.

a. Which database(s) did you use?

b. How many articles did you find?

c. How could you narrow your search?

3. Choose five articles returned by your search. For each article, provide the proper citation, the author's home institution, and the organism studied. Different journals use different citation styles. Please follow the citation example below.

Example of journal citation:

Bukovinszky T., van Veen F.J.F., Jongema Y., \& Dicke M. (2008). Direct and indirect effects of resource quality on food web structure. Science, 319, 804-807.

4. Choose one of the five articles for further study. The article must be at least four pages long and include a Title, Abstract, Introduction, Materials \& Methods, Results, and Discussion. Answer the following questions. 
a) Which type of information does the abstract contain?

b) What are the main methods used?

c) How detailed is the Materials and Methods section? Do you think you could repeat the experiment with the information given, if you had the proper equipment and experience?

d) Give two important results

e) Did the author(s) use any type of visual aids in presenting the results (graphs, tables, etc.)? If so, what did they use and were they easy to understand?

f) Briefly explain one of the figures using your own words.

g) Did the author(s) make obvious what hypothesis was being tested? Do they clearly state in the discussion section whether or not the hypothesis was supported? Do they make any recommendations for future experiments?

h) Does the references cited section follow exactly the same format as shown above? If not, give one example to show how it is different. 


\section{Appendix B. The Prototype Case}

You are a college freshman and you are very interested in biology. You liked observing frog jumps since you were a little boy. It was as if a frog made itself a beautiful sling shot when they were bouncing forward. How could frogs manage to leap such long distances? How could they become such exceptional leapers? What is the secret? Is it because they have unusually longer legs? Is it because their bones are more elastic? Is it because their muscles have special elements that generate more energy than any other animals of the same size? Is it because their joints have a special structure? You were interested in exploring this topic and you want to find some research articles that can help me understand this phenomenon.

Question 1. Before I start my research on this topic, I would like know more about the anatomy of frogs. You want to find such a book at York College Library or other CUNY libraries.

Question 2. If you want to find all the accessible E-books on frogs at York College Library or CUNY Libraries. How could you achieve that?

Question 3. In the recommended database, you want to find three peer-reviewed research articles written by researchers on the study of frog's jumping from Harvard University after 2015.

Question 4. You want to find two more peer-reviewed articles that have been done on the study of mechanical systems that imitate the movement of frogs. 


\section{Appendix C. Two Cases}

Case 1.

You liked watching frogs as a young boy. Now you are a college student and take some biological courses. You are very curious how frogs become such exceptional jumpers. You also want to know whether a robot could be designed to jump like a frog.

Exercise. Formulate three keywords from this narrative and find three peer-reviewed articles in the recommended database. (Three keywords don't have to completely and exactly come from the text)

\section{Case 2.}

An 88-year-old man had eaten 25 eggs per day for many years, yet his serum cholesterol was only in the range of 150-200 milligrams per deciliter.

Exercise. Design a research question based on your understanding of this narrative. Extract at least three keywords from your research question and locate two peer-reviewed articles in the recommended database. 